А.Л. ЗАПЛАТНИКОВ ${ }^{1}$, Д.М.Н., профессор, И.Д. МАЙКОВА ${ }^{2}$, К.М.Н., И.В. ЛЕПИСЕВА 3

1 Российская медицинская академия последипломного образования Минздрава России, Москва

2 Детская городская клиническая больница им. 3.А. Башляевой Департамента здравоохранения г. Москвы

3 Детская республиканская больница, г. Петрозаводск

\title{
РЕСПИРАТОРНЫЙ МИКОПЛАЗМОЗ
}

В ПРАКТИКЕ ВРАЧА-ПЕДИАТРА

\begin{abstract}
Респираторный микоплазмоз - группа инфекционно-воспалительных заболеваний органов дыхания, вызываемых патогенными микроорганизмами рода Mycoplasma. Установлено, что основным возбудителем при этом является Mycoplasma pneumoniae (M. pneumoniae). Значение других микоплазменных патогенов в генезе респираторных инфекций до настоящего времени остается предметом дискуссии. В связи с этим термин «респираторный микоплазмоз» в основном ассоциируется с М. pneumoniae-инфекцией [5, 7, 15, 22].
\end{abstract}

\author{
Ключевые слова: \\ респираторный микоплазмоз \\ эпидемиология \\ терапия \\ макролиды \\ азитромицин
}

Этиология. M. pneumoniae относится к роду Mycoplasma, семейству Mycoplasmatacea, классу Mollicutes. M. pneumoniae является очень мелкой, свободноживущей, грамотрицательной, факультативно-анаэробной бактерией, лишенной истинной клеточной стенки. Функции клеточной стенки выполняет 3-слойная цитоплазматическая мембрана. Из-за того, что M. pneumoniae не способна синтезировать стерины, необходимые для образования липидных слоев данной мембраны, восполнение потребностей в холестерине и других стеринах возбудитель осуществляет только за счет утилизации их из инфицированных тканей макроорганизма. Отсутствие клеточной стенки и особенности метаболизма M. pneumoniae определяют невысокую ее выживаемость вне организма-хозяина и повышенную чувствительность к факторам внешней среды. Традиционные дезинфицирующие средства, а также ультразвук, ультрафиолетовое облучение, колебания рН среды и температуры обладают выраженным ингибирующим влиянием на M. pneumoniae [5, 8, 22].

Эпидемиология. Респираторный микоплазмоз широко распространен в человеческой популяции.Установлено, что в обычных условиях на долю М. pneumoniae-инфекций приходится до 10-16\% всех случаев острых респираторных заболеваний, а в период эпидемических вспышек этиологическое значение М. pneumoniae может возрастать до 30-40\%. При этом отмечено, что респираторный микоплазмоз характеризуется определенными возрастными особенностями. Так, наиболее часто заболевание регистрируется у детей-школьников, подростков и лиц молодого возраста $[4-8,12,15-18,25]$.
Источником инфекции являются больные с манифестной и субклинической формой заболевания. Роль M. pneumoniae-носителей (как транзиторных, так и реконвалесцентных) в качестве источников инфекции признается не всеми. Передача инфекции осуществляется преимущественно воздушно-капельным путем. При этом инфицирование происходит лишь при тесном контакте между людьми, что обусловлено нестойкостью возбудителя в окружающей среде. В связи с этим типичными для M. pneumoniae являются семейные очаги инфекции, а наибольший уровень заболеваемости отмечают в организованных коллективах, особенно закрытого типа. Описаны также случаи внутригоспитальных вспышек заболевания [8, 9].

Респираторный микоплазмоз широко распространен в человеческой популячии.

Установлено, что в обычных условиях на долю М. рпеитопіае-инфекций приходится до 10-16\% всех случаев острых респираторных заболеваний, а в период эпидемических вспышек этиологическое значение М. pпеитопiae может возрастать до 30-40\%

Отмечена повсеместная регистрация респираторного микоплазмоза, но чаще заболевания встречаются в странах с умеренным климатом. При этом каждые 4-8 лет имеет место эпидемический подъем заболеваемости. М. pneumoniae-инфекция может встречаться у людей любого возраста, но наиболее часто - у детей-школьников, подростков и молодых людей. Манифестные формы заболевания также преимущественно регистрируются в указанных возрастных группах. Так, если у детей первых 5 лет жизни микоплазменные пневмонии встречаются довольно редко, то у детей школьного возраста, подростков и молодых взрослых в период эпидемического подъема заболеваемости М. pneumoniae становится одним из основных этиологических факторов внебольничной пневмонии [4, 6, 8, 17, 20, 24]. 
Инкубационный период заболевания составляет от 1 до 4 нед. Период заразительности при поражении M. pneumoniae верхних дыхательных путей - 5-7 дней, при М. pneumoniae-пневмонии - до 2-3 нед. [8, 15, 22, 25].

\section{Каждые 4-8 лет имеет место эпидемический подъем заболеваемости. М. pneuтопіае- инфекция может встречаться у людей любого возраста, но наиболее часто - у детей- школьников, подростков и молодых людей}

Патогенез. Входными воротами для М. pneumoniaeинфекции являются слизистые респираторного тракта. При этом выраженный тропизм М. pneumoniae к слизистым дыхательных путей обусловлен особенностями строения поверхностных антигенов возбудителя. Так, адгезины M. pneumoniae обеспечивают лиганд-рецепторное связывание возбудителя с эпителиальными клетками респираторного тракта [5, 8, 22]. При этом ферменты, синтезируемые микоплазмой, оказывают неблагоприятное воздействие на эпителий. Повреждение клеточной стенки эпителиоцитов сопровождается нарушением межклеточных связей, угнетением мукоцилиарного клиренса и гибелью эпителиальных клеток [3, 8, 14]. Воспаление чаще ограничивают слизистой верхних дыхательных путей и бронхов. Однако нередко (особенно у детей школьного возраста и молодых людей) инфекционный процесс распространяется на терминальные отделы респираторного тракта, приводя к развитию пневмонии. При этом отмечают дистрофию, деструкцию и метаплазию части клеток альвеолярного эпителия, а также утолщение межальвеолярных перегородок. Эпителиальные клетки на ранних этапах заболевания сохраняют связь со стенкой альвеол, но позднее слущиваются и подвергаются лизису. У детей раннего возраста при этом возможно образование гиалиновых мембран. Одновременно в легочной интерстиции отмечаются ограниченные инфильтраты, преимущественно перибронхиальные и периваскулярные, которые представлены лимфоцитамы, плазмоцитами, гистиоцитами, моноцитами и единичными нейтрофилами [3, 14].

При выраженном воспалении может развиться хронический интерстициальный легочный фиброз [26]. Описаны случаи развития генерализованной M. pneumoniaeинфекции с вовлечением в воспалительный процесс органов кровообращения, нервной системы, суставов, кожных покровов, слизистых и органов кроветворения $[10,18$,$] . В последние годы активно изучается роль М$. pneumoniae в развитии различных иммунопатологических состояний (бронхиальная астма, ревматоидный артрит, синдром Стивенса - Джонсона, иммунные цитопении и др.) [10, 19, 23].

Иммунитет. М. pneumoniae-инфекция сопровождается формированием специфических гуморальных и клеточных иммунных реакций, направленных на элиминацию возбудителя. Однако развивающийся при этом иммунитет непродолжителен, в результате чего возможно повторное заражение [6, 8, 9, 22, 25].
Клиника. Проявления М. pneumoniae-инфекции весьма вариабельны и могут характеризоваться как субклиническим, так и манифестным течением. Манифестные формы респираторного микоплазмоза у детей наиболее часто проявляются острыми воспалительными изменениями верхних дыхательных путей (ВДП). Ведущим клиническим вариантом инфекции при этом является фарингит. Реже развиваются микоплазменные ринит, синуситы, средний отит, мирингит и ларингит [25].

Отмечено, что клинические проявления M.pneumoniaeфарингита и других микоплазменных поражений ВДП имеют мало специфических черт и практически не отличаются от аналогичных заболеваний иной этиологии. Инфекция начинается остро, с подъема температуры тела до фебрильного уровня и недомогания, в ряде случаев отмечается головная боль и другие симптомы интоксикации. Возникает першение и боль в горле, чувство «заложенности носа». Реже отмечается насморк, боли в ушах и проявления конъюнктивита. Лихорадка, как правило, купируется в течение нескольких дней, но субфебрилитет может сохраняться еще на протяжении 1-2 нед. Катаральные симптомы заболевания в подавляющем большинстве случаев регрессируют в течение 7-10 дней, однако выделение возбудителя с носоглоточным секретом может отмечаться еще длительное время - до нескольких недель [9, 25].

M. pneumoniae-инфекция нижних отделов органов дыхания сопровождается развитием воспаления бронхов (микоплазменный бронхит) и легких (микоплазменная пневмония). При этом наиболее частой клинической формой заболевания является бронхит. Однако при эпидемическом подъеме заболеваемости частота развития микоплазменных пневмоний значительно возрастает. Так, установлено, что в этот период до 40-60\% всех пневмоний у детей школьного возраста имеют M. pneumoniaeэтиологию.

\section{M. pпеитопіае-инфекция сопровождается формированием специфических гуморальных и клеточных иммунных реакций, направленных на элиминацию возбудителя. Однако развивающийся при этом иммунитет непродолжителен, в результате чего возможно повторное заражение}

Клинический дебют микоплазменной пневмонии напоминает развитие М. pneumoniae-инфекции верхних дыхательных путей, но с более выраженной лихорадкой. Однако, несмотря на гипертермию, симптомы интоксикации обычно выражены неярко, что является одним из немногих специфических признаков микоплазменной пневмонии. Кроме этого, через несколько дней от начала заболевания появляется сухой, навязчивый и/или приступообразный кашель, который может отмечаться в течение длительного времени - до нескольких недель. Кашель постепенно становится продуктивным и более редким. В легких при этом могут выслушиваться рассе- 
янные сухие и разнокалиберные влажные хрипы. При рентгенологическом обследовании в легких выявляют двусторонние очаги негомогенной инфильтрации, но могут быть и односторонние инфильтративные тени. В ряде случаев (до 10\%) при микоплазменной пневмонии отмечают преходящую макулопапулезную сыпь. Заболевание, как правило, протекает нетяжело, характеризуется гладким течением и отсутствием дыхательной недостаточности или слабой ее выраженностью. В то же время у детей с иммунодефицитами, серповидно-клеточной анемией, с тяжелыми сердечно-легочными заболеваниями, а также у пациентов с синдромом Дауна имеется риск развития осложненных форм микоплазменной пневмонии [22, 25].

Учитывая отсутствие специфических клинических признаков М. pneumoniae-инфекции, верификацию заболевания проводят на основании результатов лабораторного обследования.

Лабораторная диагностика. Классические микробиологические методы малопригодны для выявления $M$. pneumoniae. Так, световая микроскопия при данной инфекции характеризуется крайне низкой чувствительностью, что связано с очень малыми размерами возбудителя. Бактериологический посев и культивирование на специально обогащенных средах требуют значительной продолжительности - от 1 до 3-6 нед.

В связи с этим в настоящее время используют методики, позволяющие верифицировать M. pneumoniae значи- тельно быстрее. При этом с помощью иммунофлюоресценции (ИФ) в биологических образцах обнаруживают антигены возбудителя, а с помощью полимеразной цепной реакции (ПЦР) - его геном [5, 22, 25]. Кроме этого, иммуноферментный анализ (ИФА), позволяющий выявить специфические антитела к M. pneumoniae. При этом выявление IgM к M. pneumoniae свидетельствует о текущей или недавно перенесенной инфекции. Наличие активного инфекционного процесса микоплазменной этиологии подтверждается также 4-кратным и более нарастанием титра IgG антител к М. pneumoniae при исследовании «парных сывороток».

\section{Клинический дебют микоплазменной пневмонии} напоминает развитие М. рпеитопіае-инфекции верхних дыхательных путей, но с более выраженной лихорадкой. Однако, несмотря на гипертермию, симптомы интоксикации обычно выражены неярко, что является одним из немногих специфических признаков микоплазменной пневмонии

При интерпретации результатов серологического исследования следует помнить о том, что в ряде случаев положительные результаты ИФА на M. pneumoniaeинфекцию могут быть связаны с перекрестным реагированием на микоплазмы других видов (ложно-позитивный

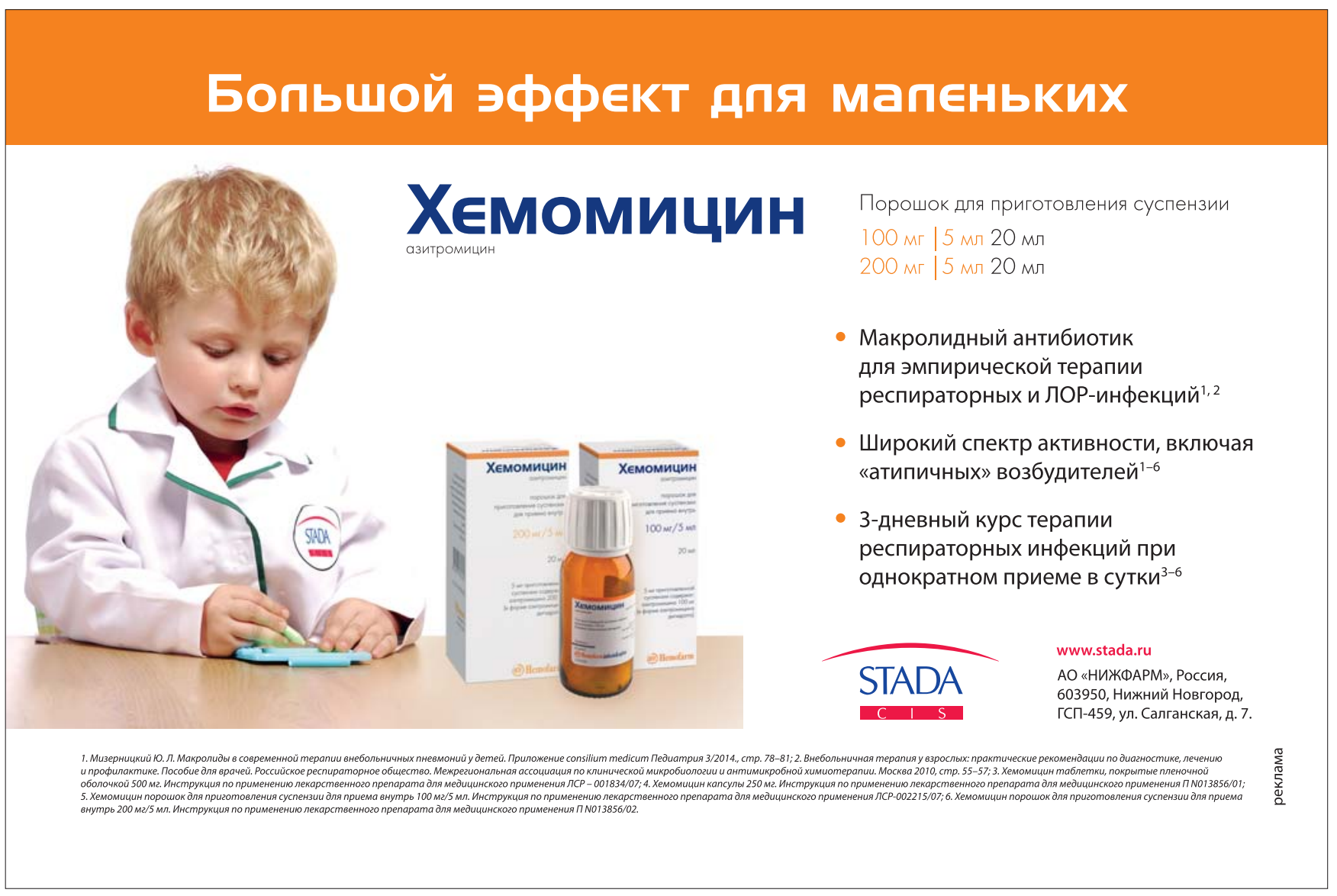


результат). Нельзя исключить и ложно-негативные результаты ИФА. Поэтому лабораторная диагностика респираторного микоплазмоза считается оптимальной, если используется комбинация методов, направленных на выявление в исследуемых материалах (назофарингеальная слизь, мокрота, плевральный экссудат и др.) антигенов возбудителя методом ИФ или его генома при помощи ПЦР, а также специфических антител IgM и IgG в сыворотке крови.

\section{Лечение респираторного микоплазмоза у детей проводится макролидными антибиотиками.}

Это связано с тем, что М. рпеитопіае устойчива к природным и полусинтетическим пенициллинам, цефалоспоринам, карбопенемам, ко-тримоксазолу, но высокочувствительна к макролидам

Этиотропная терапия. Лечение респираторного микоплазмоза у детей проводится макролидными антибиотиками. Это связано с тем, что М. pneumoniae устойчива к природным и полусинтетическим пенициллинам, цефалоспоринам, карбопенемам, ко-тримоксазолу, но высокочувствительна к макролидам [1, 6, 12].

Макролиды - группа бактериостатических антибиотиков, химическая структура которых представлена макроциклическим лактонным кольцом, связанным с одним или несколькими углеводными остатками [11]. В зависимости от числа атомов углерода в лактонном кольце различают 3 основных подкласса макролидов 14-, 15-и 16-членные макролидные антибиотики, а зависимости от происхождения выделяют природные и полусинтетические препараты. Установлено, что микробиологическая эффективность различных макролидов по отношению к М. pneumonia практически одинакова [11]. Однако при выборе препарата необходимо обращать внимание не только на эффективность антибиотика, но и на профиль его безопасности, комплаентность, а также на взаимодействие с другими лекарственными средствами.

Так, если микоплазменный бронхит или пневмония протекают с обструктивным синдромом и требуется назначение эуфиллина, то необходимо обратить внимание на совместимость макролидов и теофилиновых производных. Это связано с тем, что метаболизм данных лекарственных средств осуществляется при участии одних и тех же ферментов печени - оксидазы системы цитохрома Р450. Одновременное их применение приводит к угнетению активности цитохрома Р450. В результате этого нарушается биотрансформация эуфиллина, что приводит к повышению его сывороточной концентрации. При этом, учитывая крайне малую широту диапазона терапевтических концентраций эуфиллина, возникает реальная угроза развития его токсических эффектов (беспокойство, возбуждение, нарушение сна, мышечный тремор, тошнота, рвота, тахикардия, артериальная гипотония, сердечная аритмия; в тяжелых случаях - галлюцинации, судороги, сердечная недостаточность).
Установлено, что не все макролидные антибиотики одинаково сильно угнетают оксидазные системы печени. Так, отмечено, что максимальное влияние на цитохром Р450 оказывают 14-членные макролиды - как природные (эритромицин, олеандомицин), так и полусинтетические (рокситромицин, кларитромицин). Поэтому из-за высокого риска токсических реакций указанные макролиды нецелесообразно использовать в тех клинических ситуациях, когда дети с респираторным микоплазмозом одновременно получают не только теофиллин, но и другие препараты, в метаболизме которых принимает участие цитохром P450 (карбамазепин, терфенадин, дигоксин и др.) [2, 11]. В этих случаях предпочтение должно отдаваться 15-(азитромицин) или 16-членным макролидам, которые обладают наименьшим ингибирующим влиянием на цитохром P450 [1, 11].

Аазитромицин относится к 15-членным макролидам антибиотикам. Необходимо отметить, что сегодня на рынке имеется большое количество генериков азитромицина. Это связано с высокой их востребованностью при лечении внебольничных инфекций дыхательных путей благодаря клинической эффективности и оптимальному комплаенсу. Возникает вопрос, какому из генериков азитромицина можно доверять и отдавать предпочтение. Для ответа на этот вопрос было проведено специальное сравнительное исследование по оценке клинической и фармако-экономической эффективности азитромицина 5 компаний-производителей (необходимо отметить, что исследование было проведено у взрослых пациентов с нетяжелым течением внебольничной пневмонии) [27]. Наиболее высокая клиническая эффективность была зарегистрирована в группах больных, получавших Хемомицин и оригинальный азитромицин (80\%). Также стоит отметить наименьшие прямые медицинские затраты при использовании Хемомицина по сравнению с азитромицином других фармацевтических компаний.

\section{Азитромицин относится к 15-членным макролидам антибиотикам. Необходимо отметить, что сегодня на рынке имеется большое количество генериков азитромицина. Это связано с высокой их востребованностью при лечении внебольничных инфекций дыхательных путей благодаря клинической эффективности и оптимальному комплаенсу}

Особенностью азитромицина является его фармакокинетика. Период полувыведения азитромицина составляет 65-72 ч, что объясняется существенным накоплением антибиотика в тканях с последующим медленным его высвобождением. Это определяет возможность назначения азитромицина коротким курсом с использованием всей суточной дозы за один прием. Так, согласно официальной инструкции, прием препарата 1 раз в сутки, продолжительность терапии - 3 дня, режим дозирования азитромицина (Хемомицин) выглядит следующим образом: детям до 12 лет порошок для приготовления суспензии для приема внутрь 100 мг/5 мл и 
200 мг/5 мл. С 12 лет возможно применение Хемомицина в форме таблеток 500 мг и капсул 250 мг, с 16 лет применяется Хемомицин (лиофилизат для приготовления раствора для инфузий 500 мг). Препараты производятся в Европе («Хемофарм», Сербия) по стандартам GMP [2].

Особо следует еще раз отметить, что в отличие от других макролидов азитромицин слабо угнетает активность изоферментов системы цитохрома P450, поэтому при одновременном назначении его с теофиллином, терфенадином, карбамазепином, дигоксином не наблюдается клинически значимых взаимодействий $[1,2,11]$.

При лечении респираторного микоплазмоза у детей старше 8 лет и у подростков, кроме макролидов, может также использоваться тетрациклиновый антибиотик доксициклин. Следует помнить, что при приеме доксициклина могут развиться диспептические нарушения, глоссит, эзофагит, анемия, нейтро- и тромбоцитопении, фотосенсибилизация и другие патологические состояния. Одновременное применение доксициклина с барбитура- тами, карбамазепином, антацидами, рифампицином приводит к уменьшению его терапевтического эффекта. Кроме возрастных ограничений (до 8 лет), препарат противопоказан также при тяжелых заболеваниях печени, лейкопениях, порфирии [2].

Продолжительность этиотропной терапии при респираторном микоплазмозе, независимо от используемых антибиотиков, не должна ориентироваться на выделение возбудителя из организма и титры специфических антител. Следует помнить, что M. pneumoniae даже после проведенного лечения может сохраняться в организме еще на протяжении нескольких недель. Специфические IgM также могут обнаруживаться еще в течение нескольких недель, а иногда и месяцев, а антитела класса IgG - даже через несколько лет после перенесенной инфекции [5, 22, 25]. В связи с этим продолжительность курса этиотропной терапии должна определяться клиническими, а не лабораторными критериями и, как правило, не превышает 7-10 дней.

\section{ЛИТЕРАТУРА}

1. Страчунский Л.С., Козлов С.Н., Белоусов Ю.Б. Практическое руководство по антиинфекционной химиотерапии. Смоленск: МАКМАХ, 2007. 464.

2. Государственный реестр лекарственных средств: МЗ РФ, 2015

3. Клембовский А.И. Микоплазменная пневмония. Морфологическая характеристика и особенности патогенеза острого воспаления легких у детей. В кн. Пневмонии у детей. Под ред. С.Ю. Каганова, Ю.Е. Вельтищева. М.: Медицина, 1985. С. 83-85.

4. Лисин В.В., Кореняко И.Е. Респираторный микоплазмоз. М., 1988. 90 с.

5. Медицинская микробиология. Под ред. В.И. Покровского, О.К. Поздеева. М: ГЭОТАР МЕДИЦИНА, 1999.

6. Инфекции респираторного тракта у детей раннего возраста. Под ред. Самсыгиной Г.А. М.: Пульс, 2013. 260 с.

7. Покровский В.И., Прозоровский С.В. Новые аспекты инфекционной пульмонологии. Эпидемиология и инфекционная патология. М., 1989. С. 12-13.

8. Прозоровский С.В., Раковская И.В., Вульфович Ю.В. Медицинская микоплазмология. М., 1995. 287 c.

9. Профилактика внутрибольничных инфекций. Руководство для врачей. Под ред. Е.П. Ковалевой и Н.А. Семиной. М., 1993.
10. Савенкова М.С. Микоплазмоз у детей: решенные и нерешенные вопросы. Bonp. совр. педиamp. 2001. Т. 1. 5: 38-46.

11. Страчунский Л.С., Козлов С.Н. Макролиды в современной клинической практике. Смоленск: Русич, 1998. 304 с.

12. Геппе Н.А., Малахов А.Б., Волков И.К. и др. К вопросу о дальнейшем развитии Научнопрактической программы по внебольничной пневмонии у детей. РМЖ. 2014. 3.

13. Таточенко В.К. Антибиотики при острых респираторных заболеваниях у детей. Consilium medicum. 2004, приложение 1: 3-6.

14. Цинзерлинг А.В. Заболевания, вызываемые микроорганизмами семейства Mycoplasmatiaceae. B кн. Современные инфекции. Патологи ческая анатомия и вопросы патогенеза. СПб.: Сотис, 1993. С. 222-228.

15. Учайкин В.Ф., Шамшева О.В., Нисевич Н.И. Инфекционные болезни у детей. М.: ГЭОТАРМедиа, 2013.

16. Чешик С.Г., Линкова С.А., Афанасьева В.А. и др. Клинико-рентгенологическая характеристика бронхолегочного микоплазмоза у детей. Педиатрия. 1987. 1: 34-39.

17. Block S, Hedrick J, Hamerschlag MR et al. Mycoplasma pneumoniae and Chlamydia pneumoniae in pediatric community-acquired pneumonia. Pediatr. Infect. Dis. J., 1995. 14: 471-477.

18. Denny FW, Clyde WA, Glezen WP. Mycoplasma pneumoniae disease: Clinical spectrum, patho- physiology, epidemiology and control. J. Infect. Dis., 1971, 123: 74.

19. Esposito S, Principi N. Asthma in children: are Chlamydia or Mycoplasma involved. Pediatr. Drugs., 2001, 3: 159-168.

20. Gendrel D. Pneumonies communautaires de l'enfant: etiologie et traitement. Arh. Pediatr., 2002, 9 (3): 278-288.

21. Michelow IC, Olsen K, Lozano J et al. Epidemiology and Clinical Characteristics of Pneumonia in Hospitalized Children. Pediatrics, 2004, 113 (4): 701-707.

22. Microbiology and Infections Diseases/ $3^{\text {rd }}$ edition. Virella G. Baltimor: Williams \& Wilkins, 1997.

23. Nicolson GL, Marwan PhD, Nasralla Y et al. Mycoplasmal Infections in Chronic Illnesses. Med. Sent., 1999, 5 (Vol. 4): 172-175.

24. Principi N, Esposito S, Blasi F, Allegra L. Role of Mycoplasma pneumoniae and Chlamydia pneumoniae in children with community-acquired lower respiratory tract infections. Clin. Infect. Dis., 2001, 32: 1281-1289.

25. Red Book: 2012. Report of the Committee on Infection Diseases. 29rd: American Academy of Pediatrics, 2012, 1058 p.

26. Tablan O, Reyes MP. Chronic intestinal pulmonary fibrosis following Mycoplasma pneumoniae pneumonia. Amer. J. Med., 1985, 79: 268-270.

27. Смоленов ИВ, Красильникова АВ. Фармакоэкономические аспекты применения азитромицина различных производителей при внебольничных пневмониях у взрослых. Фарматека, 2003. 13: 78-87. 